\title{
【Original Article】
}

\section{Perspectives on the Continuous Medication Monitoring Function of Pharmacies in the Community Health Care System: A Nationwide Survey in Japan}

\author{
Yasunori OSANAI, Hidehiko SAKURAI*
}

Hokkaido University of Science

\begin{abstract}
【ABSTRACT】
Objective: The objective of this study was to identify the perceived importance of various pharmacy functions among residents in the community health care system.

Methods: We conducted an online survey of nationwide panelists enrolled by a research company to assess the perceived degree of importance of having a pharmacy that performs various functions in the community health care system (i.e., "comprehensive importance").

Results: "Comprehensive importance" was compared among 2,400 respondents disaggregated into several groups. The results revealed that "encouragement for medical consultations at medical institutions" had a strong effect on "comprehensive importance".

Conclusion: The results of this survey highlight the need for preventive medical care and a further expansion of the consultation function at pharmacies in the future.
\end{abstract}

\begin{abstract}
【Key words】
continuous medication monitoring function, consultation, community health care system, encouragement for medical consultations at medical institutions
\end{abstract}

\section{INTRODUCTION}

In 2015, to envisage concerted efforts aimed at improving health support functions, the Japanese Ministry of Health, Labour and Welfare (MHLW) announced "kanjya no tame no yakkyoku vision". Subsequently, in 2016, the MHLW started a system consisting of a "health support pharmacy" that can perform health consultations while allowing patients to use pharmacies continuously. The direct advantages of this function are that it secures patient information, provides appropriate medical services such as 24-hour correspondence, and supports health promotion and maintenance (hereafter, this is referred to as the pharmacy's "continuous medication monitoring function”).

In a previous study, we investigated the status of consultation services regarding drugs dispensed at pharmacies on public holidays and during night hours, which is a basic function of a pharmacy. In addition, we investigated the content of these consultations and assessed the users' characteristicsand and respective needs ${ }^{1,2)}$. Currently, pharmacies in some areas provide 24-hour consultation services. Since the number of consultations provided at a pharmacy is relatively

Accepted Date: October 13, 2020

15-4-1, Maeda 7-jo, Teine-ku, Sapporo-shi, Hokkaido, 006-8585, Japan Tel: +81 11-676-8732 Fax: +81 11-676-8666

E-mail: hsakurai@hus.ac.jp 
constant $^{3)}$, it is feasible for pharmacies to cater to patient needs in regard to not only the preparation of medicines, but also consultations. Although several studies have investigated consultations in various medical specialties ${ }^{4-9)}$, few have investigated the consultations provided at health support pharmacies. In addition, hygiene promotion and consultations pertaining to home-based medical care are considered an important pharmacy function. However, as these activities are important elements of community medicine ${ }^{10)}$, their current status has not been investigated adequately.

Concerning the continuing evolution of pharmacies as important outposts for the delivery of community health care services, the separation of dispensing and prescribing functions is important; however, the current status of pharmacies in this regard is not well characterized. Before the separation of these functions, it was assumed that medical institutions did not provide sufficient dispensing and consultation services, especially during holidays and night hours. The separation of dispensing and prescribing functions at pharmacies represents an upgrade of their role as a medical institution. Pharmacies are thus poised to play a wider role as a medical facility in future, not only as a facility that dispenses medicine. Furthermore, pharmacies should be actively integrated in the local health care delivery system. Several studies have investigated the functioning of pharmacies and the role of pharmacists ${ }^{11,12)}$. Although the functions of pharmacies have been surveyed and studied as service providers, to our knowledge, no previous studies have focused on the importance of the functions as expected by users who are service consumers in the community health care system while targeting people living in various parts of Japan rather than in limited areas. Since the functioning of pharmacies should be closely aligned with local needs according to the characteristics of the area and users, it is important to grasp the details of pharmacy functions regarded as important by users.

Therefore, in this study, with the aim of clarifying not only the characteristics of the continuous medication monitoring functions of pharmacies, but also their importance to community-dwelling individuals in the regional medical care system, the authors conducted a survey covering those with diseases or who were frequently using pharmacies, irrespective of basic attributes such as sex, as well as healthy people and those who were not familiar with pharmacies, assuming that pharmacies will be able to be used as health information transmission bases in the future.

\section{MATERIALS AND METHODS}

\section{Survey participants and methods}

We conducted an online cross-sectional survey from May 16 to 19, 2018. The survey participants were men and women aged 20 years or older from panels in 47 prefectures nationwide that had been registered in advance with Cross Marketing Group, Inc. (Tokyo, Japan). Based on data obtained from the Statistics Bureau, Ministry of Internal Affairs and Communications, and MHLW, the sex ratio and age structure of each region were calculated based on demographic trends, the aged population, and the area distribution of the population, and then respondents were extracted to secure the necessary number. Overall, 1,200 men (50.0\%) and 1,200 women (50.0\%) were extracted. Considering the actual situation of social resources related to medical care, including health centers, the regions were divided into two groups: urban areas (core cities and above) and rural areas (other). There were 1,200 (50.0\%) urban dwellers and 1,200 (50.0\%) rural dwellers. To distinguish older from younger people in the age structure, the respondents were divided into two groups: those aged 20-65 years and those aged 65 years or older. There were 1,600 (66.7\%) respondents aged 20-65 years and 800 (33.3\%) aged 65 years or older. The mean age of all respondents was 52.9 years. An Internet survey regarding the importance of the pharmacy' s continuous medication monitoring functions was conducted on all 2,400 subjects. The exclusion criteria were: medical professionals, publishing/media professionals, and survey company personnel. The sex, age, and residential area of the respondents were also determined using the panel registry information.

\section{Survey items}

The principal survey items included various situations (e.g., whether the respondent had a chronic disease, used a pharmacy regularly, had a "the family pharmacy", had health problems).

Since consultations at pharmacies are considered to be a service that is more desirable for those who have health concerns or are already suffering from various diseases, the target group for the multiple regression analysis was further divided into two groups according to health conditions. In addition, it is assumed that 
the importance of individual pharmacy functions are influenced by user's sense of familiarity with the pharmacy itself and degree of understanding regarding the pharmacy's operations. Therefore, the analysis on the importance of the pharmacy functions was carried out by dividing the respondents into two groups according to their level of familiarity with the family pharmacy, such as their frequency of use. A total of four groups were targeted for the multiple regression analysis: 1) individuals with good health status; 2) individuals with health-related problems; 3 ) individuals with a sense of closeness to the pharmacy; and 4) individuals with little or no sense of closeness to the pharmacy.

The pharmacy's continuous medication monitoring functions were assessed using the following 16 question items, which were adopted from items used in previous studies and the "Way of thinking about health support pharmacies” prepared by the Japan Pharmaceutical Association ${ }^{1,2,13-15)}$ : (i) whether there was a pharmacy in the neighborhood; (ii) the prevention of multiple drug prescriptions; (iii) whether there was an expert pharmacist (authorized by a pharmaceutical society); (iv) whether there was a place for consultations with adequate privacy; (v) awareness about generic drugs; (vi) encouragement for medical consultations at medical institutions; (vii) ongoing feedback about the effects of medication; (viii) 24-hour correspondence; (ix) availability of pharmacy services on Sundays and public holidays; (x) support to prevent patients from forgetting to take medication; (xi) prevention of duplicate administration; (xii) continuous monitoring of side effects; (xiii) the medicine storage system; (xiv) the disposal of self-use needles; (xv) obtaining information about drug-drug interactions; and (xvi) barrier-free structures. Finally, we comprehensively surveyed the respondents' perceived degree of importance of having a pharmacy that performs continuous medication monitoring functions in the community health care system (hereafter, “comprehensive importance”). The respondents were asked to rate the self-perceived utility of each item on a 7-point Likert scale (from $1=$ not important at all to $7=$ very important).

\section{Statistical analysis}

\section{Student's $t$-test}

We classified the respondents into two groups based on two attributes-health condition and sense of closeness to the pharmacy-and then compared the mean "comprehensive importance" scores and conducted an analysis between groups using Student's $t$-test.

\section{Multiple regression analysis}

Multiple regression analysis (stepwise method) was used to identify the pharmacy functions perceived as an important part of the community health care system among the four groups of respondents using “comprehensive importance” as the dependent variable and the 16 items regarding the pharmacy's "continuous medication monitoring function" as the independent variables. The variance inflation factor was calculated for each independent variable, all of which were less than 3 , indicating the lack of a multiplex collinearityrelated influence. The level of statistical significance was set at 5\%. IBM SPSS Statistics 25 (Armonk, NY, USA) was used to perform all statistical analyses.

\section{Ethics review board}

This study was performed in accordance with the principles of the Declaration of Helsinki and approved by the ethics review committee of the Hokkaido University of Science (Approval No. 17-04-019, 2017/10/30).

\section{RESULTS}

\section{Descriptive statistics}

Table 1 shows the respondents' attributes. The majority of the respondents could be placed in the following groups: respondents that do not suffer from a chronic disease $(1,868 ; 77.8 \%)$, respondents that do not use the pharmacy regularly $(1,612 ; 67.2 \%)$, respondents that not decide which family pharmacy they will go to $(1,714 ; 71.4 \%)$, and respondents that do not feel uneasy about their health $(1,353 ; 56.4 \%)$.

\section{Results of comparisons}

(1) Comparison of the "comprehensive importance" of the community pharmacy's continuous medication monitoring function

Table 2 presents the results of Student's $t$-test. Regarding the analysis based on health conditions, significant differences were found only in the group of individuals with health-related problems compared with the group with a good health status $(P<0.000)$. On the other hand, regarding the sense of closeness to the pharmacy, significant differences were only found in the group of individuals who had a sense of closeness to the pharmacy compared with those who had little or no sense of closeness to the pharmacy $(P<0.000)$. 
Table 1 Distribution of Respondent Characteristics

\begin{tabular}{|c|c|c|c|c|}
\hline & question item & & number of item & rate $(\%)$ \\
\hline \multirow{8}{*}{$\begin{array}{l}\text { Various } \\
\text { situations }\end{array}$} & \multirow{2}{*}{ Chronic disease } & Yes & 532 & 22.2 \\
\hline & & No & 1,868 & 77.8 \\
\hline & \multirow{2}{*}{$\begin{array}{l}\text { The periodical use } \\
\text { of the pharmacy }\end{array}$} & Yes & 788 & 32.8 \\
\hline & & No & 1,612 & 67.2 \\
\hline & \multirow{2}{*}{ Family pharmacy } & Yes & 686 & 28.6 \\
\hline & & No & 1,714 & 71.4 \\
\hline & \multirow{2}{*}{$\begin{array}{l}\text { Uneasiness } \\
\text { for the health }\end{array}$} & Yes & 1,047 & 43.6 \\
\hline & & No & 1,353 & 56.4 \\
\hline
\end{tabular}

Table 2 The Result of the Comparison of "Comprehensive Importance" for The Pharmacy's Continuous Medication Monitoring Function of Community Pharmacy

\begin{tabular}{|c|c|c|c|c|c|}
\hline & \multicolumn{2}{|c|}{ Health Condition } & \multirow{2}{*}{$t$} & \multirow{2}{*}{$P$} & \multirow{2}{*}{ Effect size $(r)$} \\
\hline & Good & No-good & & & \\
\hline \multirow[t]{3}{*}{$\begin{array}{l}\text { Comprehensive } \\
\text { Importance }\end{array}$} & $4.92 \pm 1.17$ & $5.31 \pm 1.13$ & 5.781 & $P<0.000$ & 0.14 \\
\hline & \multicolumn{2}{|c|}{$\begin{array}{l}\text { Sense of Closeness } \\
\text { for the Pharmacy }\end{array}$} & \multirow{2}{*}{$t$} & \multirow{2}{*}{$P$} & \multirow{2}{*}{ Effect size $(r)$} \\
\hline & High & Low & & & \\
\hline $\begin{array}{l}\text { Comprehensive } \\
\text { Importance }\end{array}$ & $5.29 \pm 1.17$ & $4.96 \pm 1.11$ & 5.308 & $P<0.000$ & 0.12 \\
\hline
\end{tabular}

Student's $t$ test was used for group comparisons. Significant differences are $P<0.05$.

However, both effect sizes, which are standardized measures of the degree of substantial difference unaffected by sample size, were small to be taken into consideration $(\mathrm{r}=0.14, \mathrm{r}=0.12)$.

(2) Factors related to health conditions that affected "comprehensive importance"

Table 3 presents the results of the multiple regression analysis.

\section{Individuals with health-related problems}

The derived regression equation for "comprehensive importance” included seven items. The regression equation showed that "encouragement for medical consultations at health institutions" and "placement of an expert pharmacist" (standardized coefficient: both 0.186) had the strongest effects on "comprehensive importance." In this group, in contrast to individuals in the good health status group, "support to prevent patients from forgetting to take medication" and "whether there was an expert pharmacist (authorized by a pharmaceutical society)" had an effect on “comprehensive importance”.

\section{Individuals with good health status}

The derived regression equation for "comprehensive importance" included nine items. "Obtaining information about drug-drug interactions" (standardized coefficient: 0.200 ) had the strongest effect on “comprehensive importance". In this group, in contrast to individuals in the health-related problems group, "24-hour correspondence” and "availability of pharmacy services on Sundays and public holidays" had an effect on "comprehensive importance".

(3) Factors having an effect on "comprehensive importance" in regard to the sense of closeness to the pharmacy

Table 4 presents the results of the multiple regression analysis.

Individuals with a sense of closeness to the pharmacy The regression equation for "comprehensive importance" included seven items. "Prevention of multiple drug prescriptions" (standardized coefficient: 0.169) had the strongest effect on "comprehensive importance." In this group, in contrast to individuals 
Table 3 Factors Having an Effect on "Comprehensive importance" about Health Condition

\begin{tabular}{|c|c|c|c|c|c|c|c|}
\hline \multicolumn{4}{|c|}{ Individuals with health-related problems $(\mathrm{n}=369)$} & \multicolumn{4}{|c|}{ Individuals with good health status $(\mathrm{n}=845)$} \\
\hline Factors having an effect & $\mathrm{B}$ & SE B & $\beta$ & Factors having an effect & $\mathrm{B}$ & SE B & $\beta$ \\
\hline $\begin{array}{l}\text { Continuous monitoring of } \\
\text { side effects }\end{array}$ & 0.118 & 0.057 & $0.121^{*}$ & $\begin{array}{l}\text { Obtaining information } \\
\text { about drug-drug interactions }\end{array}$ & 0.173 & 0.033 & $0.200^{* * *}$ \\
\hline $\begin{array}{l}\text { Encouragement for medical } \\
\text { consultations at medical institutions }\end{array}$ & 0.192 & 0.046 & $0.186^{* * *}$ & Barrier-free structure & 0.137 & 0.024 & $0.163^{* * *}$ \\
\hline $\begin{array}{l}\text { Expert pharmacist } \\
\text { (authorized by a pharmaceutical society) }\end{array}$ & 0.174 & 0.039 & $0.186^{* * *}$ & $\begin{array}{l}\text { Ongoing feedback about } \\
\text { the effects of medication }\end{array}$ & 0.103 & 0.031 & $0.118^{* *}$ \\
\hline $\begin{array}{l}\text { Place for consultations } \\
\text { with adequate privacy }\end{array}$ & 0.113 & 0.052 & $0.127^{* *}$ & $\begin{array}{l}\text { Availability of pharmacy services } \\
\text { on Sundays and public holidays }\end{array}$ & 0.064 & 0.023 & $0.076^{* *}$ \\
\hline $\begin{array}{l}\text { Ongoing feedback about } \\
\text { the effects of medication }\end{array}$ & 0.119 & 0.043 & $0.127^{*}$ & $\begin{array}{l}\text { Continuous monitoring of } \\
\text { side effects }\end{array}$ & 0.102 & 0.033 & $0.115^{* *}$ \\
\hline Pharmacy of the neighborhood & 0.112 & 0.045 & $0.116^{* *}$ & $\begin{array}{l}\text { Prevention of duplicate } \\
\text { administration }\end{array}$ & 0.091 & 0.030 & $0.106^{* *}$ \\
\hline \multirow[t]{3}{*}{$\begin{array}{l}\text { Support to prevent patients } \\
\text { forgetting to take medication }\end{array}$} & 0.105 & 0.029 & $0.110^{*}$ & $\begin{array}{l}\text { Encouragement for medical } \\
\text { consultations at medical institutions }\end{array}$ & 0.072 & 0.028 & $0.077^{*}$ \\
\hline & & & & 24- hour correspondence & 0.058 & 0.023 & $0.068^{*}$ \\
\hline & & & & Pharmacy of the neighborhood & 0.072 & 0.029 & $0.082^{*}$ \\
\hline Adjusted $\mathrm{R}^{2}$ value & & 0.607 & & Adjusted $\mathrm{R}^{2}$ value & & 0.628 & \\
\hline $\mathrm{F}$ value & & 82.321 & & $\mathrm{~F}$ value & & 159.12 & \\
\hline
\end{tabular}

※ B: Non- standardized coefficients, SE B: Standard error, $\beta$ : Standardized coefficients Method: Stepwise method, ${ }^{*} P<0.05,{ }^{*} P<0.01,{ }^{* * *} P<0.001$

Table 4 Factors Having an Effect on "Comprehensive importance" about Sense of Closeness for the Pharmacy

\begin{tabular}{|c|c|c|c|c|c|c|c|}
\hline \multicolumn{4}{|c|}{ Individuals with a sense of closeness to the pharmacy $(\mathrm{n}=434)$} & \multicolumn{4}{|c|}{ Individuals with little sense of closeness to the pharmacy $(n=1,360)$} \\
\hline Factors having an effect & $\mathrm{B}$ & SE B & $\beta$ & Factors having an effect & B & SE B & $\beta$ \\
\hline $\begin{array}{l}\text { Ongoing feedback about } \\
\text { the effects of medication }\end{array}$ & 0.160 & 0.050 & $0.166^{* *}$ & $\begin{array}{l}\text { Obtaining information } \\
\text { about drug-drug interactions }\end{array}$ & 0.130 & 0.025 & $0.145^{* * *}$ \\
\hline $\begin{array}{l}\text { Prevention of multiple } \\
\text { drug prescriptions }\end{array}$ & 0.154 & 0.046 & $0.169^{* *}$ & $\begin{array}{l}\text { Encouragement for medical } \\
\text { consultations at medical institutions }\end{array}$ & 0.153 & 0.021 & $0.162^{* * *}$ \\
\hline $\begin{array}{l}\text { Place for consultations } \\
\text { with adequate privacy }\end{array}$ & 0.131 & 0.040 & $0.141^{* *}$ & $\begin{array}{l}\text { Continuous monitoring of } \\
\text { side effects }\end{array}$ & 0.119 & 0.025 & $0.128^{* *}$ \\
\hline $\begin{array}{l}\text { Encouragement for medical } \\
\text { consultations at medical institutions }\end{array}$ & 0.155 & 0.039 & $0.154^{* * *}$ & Pharmacy of the neighborhood & 0.086 & 0.022 & $0.095^{* * *}$ \\
\hline $\begin{array}{l}\text { Expert pharmacist } \\
\text { (authorized by a pharmaceutical society) }\end{array}$ & 0.150 & 0.041 & $0.165^{* * *}$ & 24- hour correspondence & 0.065 & 0.017 & $0.076^{* * *}$ \\
\hline Pharmacy of the neighborhood & 0.080 & 0.041 & $0.101^{*}$ & Medicine storage system & 0.078 & 0.022 & $0.085^{* * *}$ \\
\hline \multirow[t]{5}{*}{ Barrier- free structure } & 0.071 & 0.034 & $0.082^{*}$ & $\begin{array}{l}\text { Prevention of duplicate } \\
\text { administration }\end{array}$ & 0.091 & 0.022 & $0.103^{* * *}$ \\
\hline & & & & $\begin{array}{l}\text { Place for consultations } \\
\text { with adequate privacy }\end{array}$ & 0.058 & 0.020 & $0.065^{* *}$ \\
\hline & & & & Barrier-free structure & 0.056 & 0.019 & $0.063^{* *}$ \\
\hline & & & & $\begin{array}{l}\text { Availability of pharmacy services } \\
\text { on Sundays and public holidays }\end{array}$ & 0.046 & 0.018 & $0.053^{* *}$ \\
\hline & & & & $\begin{array}{l}\text { Ongoing feedback about } \\
\text { the effects of medication }\end{array}$ & 0.061 & 0.026 & $0.067^{*}$ \\
\hline Adjusted $R^{2}$ value & & 0.646 & & Adjusted $R^{2}$ value & & 0.685 & \\
\hline F value & & 113.883 & & F value & & 269.529 & \\
\hline
\end{tabular}

※ B: Non- standardized coefficients, SE B: Standard error, $\beta$ : Standardized coefficients Method: Stepwise method, ${ }^{*} P<0.05,{ }^{* *} P<0.01,{ }^{* * *} P<0.001$ 
in the group with little or no sense of closeness to the pharmacy, "whether there was an expert pharmacist (authorized by a pharmaceutical society)" had an effect on "comprehensive importance".

Individuals with little or no sense of closeness to the pharmacy

The regression equation for "comprehensive importance" included 11 items. Under the pharmacy's continuous medication monitoring function, "encouragement for medical consultations at health institutions" (standardized coefficient: 0.162) had the strongest effect on "comprehensive importance".

\section{DISCUSSION}

The objective of this study was to identify the pharmacy functions considered important by users in the community health care system.

First, regarding the results of the Student's $t$-test for the comparison of "comprehensive importance" between groups regarding the community pharmacy's continuous medication monitoring function, although a significant difference was observed between groups based on Student's $t$-test, the effect sizes, which are standardized measures of the degree of substantial difference unaffected by sample size, were small to be taken into consideration. However, the mean score for the selfperceived utility of each item was approximately 5 points (on a 7-point scale), and was high regardless of health condition and sense of closeness to the pharmacy. This result indicates that the pharmacy's continuous medication monitoring function is highly important among individuals with health-related problems and who have a sense of closeness to the pharmacy, suggesting that pharmacies should be regarded as an important local health resource.

Next, regarding the results of the multiple regression analysis, "encouragement for medical consultations at medical institutions", “ongoing feedback about the effects of medication", and "whether there was a pharmacy in the neighborhood" influenced "comprehensive importance" in all four groups, which suggests that the pharmacy's continuous medication monitoring function is important for promoting not only healthy maintenance and treatment, but also a good physical condition. The presence of a pharmacy in the neighborhood is of paramount importance. This particular aspect is not a function of an individual pharmacy, but should be prioritized at the policy level by the government. In addition, "encouragement for medical consultations at medical institutions”, which is a preventive correspondence, had a greater influence than did the other items in three of the four groups.

These findings imply that pharmacies can play important roles, such as following up patients, as a precursor for medical advice. Therefore, the consultation function was the single most important to reinforce the pharmacy function. In two of the four groups, a large number of variables were found to affect "comprehensive importance". This finding could have been the result of many items having already been viewed as a pharmacy function by the respondents. In addition, as shown in the good health status, "24-hour correspondence" and "availability of pharmacy services on Sundays and public holidays" are important areas for expanding the role of the pharmacy in the community health care system.

In addition, regarding the characteristics of the individual target groups, among those who were in poor health, the availability of "an expert pharmacist (authorized by a pharmaceutical society)" strongly affected the "comprehensive importance" function, which was different from the other groups. Individuals with health-related problems regarded utilization of the pharmacy as a solution to a health problem; in this group, a function to facilitate the maintenance of health and treatment was revealed to be important. Furthermore, unlike individuals with good health status, the direct function of treatment such as "support to prevent patients from forgetting to take medication" affected the importance. It is plausible that, when an expert pharmacist is available at the pharmacy, individuals with chronic diseases are more likely to feel secure.

The group with a strong sense of closeness with the pharmacy were likely to have a deep understanding of the pharmacy because of the extensive use of pharmacy services and the numerous opportunities to contact a pharmacist. In this group, the specialty function of the pharmacy and the pharmacist strongly affected "comprehensive importance". This result revealed that the pharmaceutical management function was important, likely because of the respondents' image of a conventional pharmacy. Further, these findings suggest the importance of widening the scope of services and basic functions of the pharmacy, such as whether it has an expert pharmacist (authorized by a pharmaceutical society).

This study did have some limitations. First, the participants were general users, so it is possible that a low level of awareness and understanding of each 
pharmacy function may have influenced the results. Second, in this Internet survey, the respondents were assumed to be relatively healthy people who were able to operate a personal computer; thus, it is difficult to confirm whether they consisted of many older people. These two conditions had a negative influence on some of the obtained results. These are issues that should be addressed in future research.

The results of the present study highlight the need for ongoing efforts to improve the functioning of pharmacies. Some of the main improvements required, in addition to the basic dispensing function, include improved management, the provision of more opportunities for interaction with users, and a broadened scope of services, such as the provision of health education and nutritional counselling. Conversely, a major strength of the present study is the large sample size. The insights gained from this study may help promote the evolution of pharmacies as medical institutions that can help bridge the gaps in the delivery of health services.

\section{CONCLUSION}

We analyzed four groups of respondents in the present study. "Encouragement for medical consultations at medical institutions" had a stronger effect than did the other items in three of the four groups. These results reveal that preventive medical care is an important function of pharmacies. It is therefore important to strengthen the functioning of pharmacies by further expanding the consultation function in the future.

To achieve this, pharmacies must expand the consultation function of "encouragement for medical consultations at medical institutions" and "ongoing feedback about the effects of medication” by taking cognizance of the patient's living environment. In addition, multidisciplinary cooperation is important to provide high quality support for home-based care.

\section{SUBVENTION}

None declared.

\section{CONFLICT OF INTERESTS}

None declared.

\section{REFERENCES}

1) Osanai Y, Kimura R, Takasugi K, et al. Investigation of the Potential Needs and Peace of Mind of Patients in Relation to Out-of-Hours Pharmacy Services. Jpn. J. Soc. Pham. 2017;36(2):106-117. ( in Japanese )

2) Osanai Y, Kimura R, Takasugi K, et al. Difference in Important about Consultation Contents of Medicine in Out-of-Hours and the Time of Opening of a Pharmacy and Evaluation. Jpn. J. Pharm. Health Care Sci. 2018; 44(6):288-298. ( in Japanese )

3) Doi N, Tsuboi S, Nakazawa T, et al. Usefulness of Medication Notebooks Evaluated Based on the Type of Questions Received by the 24-hour Consultation Service of an Insurance-based Dispensing Pharmacy. Jpn. J. Pharm. Health Care Sci. 2012;38(3):204-209. ( in Japanese )

4) Shichi S, Fujita T, Kawakami E, et al. The important of provision of information toward general population in drugstore. Jpn. J. Drug Inform. 2009;1 1(2):88-95. ( in Japanese )

5) Okumura Y, Oda M, Saitoh K. Analysis of Questions Raised by Medical Consumers with Telephone. Jpn. J. Drug Inform. 2015;17(1):34-38. ( in Japanese )

6) Satoh K, Moriyama Y. Kanjya ga motomeru kakaritukeyakuzaishi towa. Rx Info. 2016;22(14):1896-1904. ( in Japanese )

7) Suzuki J, Senba Y, Kaiho F. The Actual State of Understanding and Utilizataion of "Home Pharmacy" in Residents and Their Regional Differences. YAKUGAKU ZASSHI. 2011;131(7):1127-1134. ( in Japanese )

8) Kamei M, Teshima K, Fukushima N, et al. Investigation of Patients' Demand for Community Pharmacies: Relationship between Pharmacy Services and Patient Satisfaction. YAKUGAKU ZASSHI. 2001;121(3):215-220.

9) Onda M, Fujii Y, Yamamichi Y, et al. Structural Features of Pharmacy Function: The Analysis Using Structural Equation Modeling. YAKUGAKU ZASSHI. 2006;126(10): 965-971.

10) Suzuki J, Ohtsu Y, Hashimoto M, et al. The Actual State of Medical Activities as "Home Pharmacy" Including Preventive Medicine in Community Pharmacy and Their Regional Differences. YAKUGAKU ZASSHI. 2008;128(12): 1819-1831. ( in Japanese )

11) Misawa J. Effects of Regional Health Care Resources on Self-rated Health. The Japanese Journal of Health and Medical Sociology. 2011;22(1):69-81. ( in Japanese )

12) Tachi T, Yoshida A, Sugita I, et al. Survey on Pharmacy Services as "Health Support Pharmacy" in Gifu City. Jpn. J. Pharm. Health Care Sci. 2016;42(6):429-444. ( in Japanese ) 
13) Misawa J. Effect of Neighborhood Health Care Resources on the Sense of Security of Residents. Journal of the Japan Society for Healthcare Administration. 2011; 48(2):65-72. ( in Japanese )

14) Takahashi K, Hishinuma M, Matsumoto J, et al. Characteristics of the Users of Health Consultation Service Offered by a Nursing College. Journal of St.
Luke’s Society for Nursing Research. 2007;11(1):90-99. (in Japanese )

15) Fukui S, Otoguro C, Ishikawa T, et al. The need for health consultation services and related factors among non-users of health consultation services residing in urban public apartment complexes. Japanese Journal of Public Health. 2013; 60(12): 745-753. ( in Japanese ) 